\title{
The first Record of Plicidentine in Varanopseidae (Synapsida, Pelycosauria)
}

\author{
Michael Laaß ${ }^{1, a^{*}}$ and Burkhard Schillinger ${ }^{2, b}$ \\ 1,2 Technical University of Munich, Heinz Maier-Leibnitz Centre and Faculty of Physics E21, \\ Lichtenbergstraße 1, D-85747 Garching, Germany \\ amichael.laass@gmx.de, bburkhard.schillinger@frm2.tum.de \\ * corresponding author
}

Keywords: Neutron tomography, Plicidentine, Pelycosauria, Synapsida, Varanosaurus

\begin{abstract}
Infolded dentine (plicidentine) around the pulp cavities of the tooth roots is an ancient dental feature of fishes (sarcopterygians and actinopterygians) and several basal tetrapod groups. But, plicidentine is completely unknown in synapsids except some sphenacodontid pelycosaurs. An investigation of a skull of Varanosaurus acutirostris (Synapsida, Pelycosauria, Varanopsidae) by means of neutron tomography showed that plicidentine is also present in another group of pelycosaurs and was obviously wider distributed among basal synapsids than previously thought. Furthermore, the presence of plicidentine in this taxon with relatively short tooth roots supports the hypothesis that plicidentine played a functional role in strengthening tooth attachment.
\end{abstract}

\section{Introduction}

Usually, vertebrate teeth are constructed by three kind of hard-tissue. The main body of the tooth root and the crown consists of dentine. The dentine body of the tooth crown is covered by a cap of enamel. In contrast, the dentine, which forms the tooth root, is surrounded by a thin layer of cementum. In some vertebrate groups the dentine layer may be infolded around the pulp cavity at the base of the tooth root. This special kind of dentine is named plicidentine. According to the definition of E.E. Maxwell et al. [1] plicidentine includes both simple as well as complex infolding of dentine structures.

Plicidentine is known from several basal vertebrate groups: actinopterygian and sarcopterygian fishes, some basal tetrapods, amphibians, parareptiles, captorhinids, reptiles and ichthyosaurs (see [1, 2] and references therein). As summarized by K.S. Brink et al. [2] plicidentine has been interpreted as a phylogenetically constrained feature of major vertebrate groups, as a structure to strengthen tooth attachment or a combination of both.

Remarkably, up to 2014 plicidentine was completely unknown in synapsids. Sectioning of the tooth roots of some sphenacodontid pelycosaurs showed that plicidentine was also present in basal synapsids ([2, 3]). However, several phylogenetic analyses revealed that sphenacodontians represent the most derived pelycosaurian clade [4-6]. This result as well as the fact that plicidentine is a typical feature of anamniote and basal tetrapod groups suggests that it was probably also present in more basal pelycosaur groups. As described in the following sections our investigation of a skull of Varanosaurus acutirostris showed that this is the case.

\section{Material and Methods}

Material. Subject of our investigation was the holotype of the skull of Varanosaurus acutirostris (Synapsida, Pelycosauria, Varanopseidae) from the collection of the Bayerische Staatssammlung in Munich (inventory number BSPG 1901 XV 20, Fig. 1). The specimen derives from the 
Craddock Bonebed, Craddock ranch north of Seymour, Baylor County, Texas, USA. This horizon belongs to the Arroyo Formation, Clear Fork Group, Lower Permian [6].

The specimen has been firstly described by F. Broili [7]. Further anatomical observations were published by F. Broili [8] and D.M.S. Watson [9]. A modern description and reconstruction of the skull have been provided by D.S. Berman et al. [6]. Except of a slight lateral compression, the skull is well preserved. It only lacks small parts of the basicranium and the caudal part of the mandible.
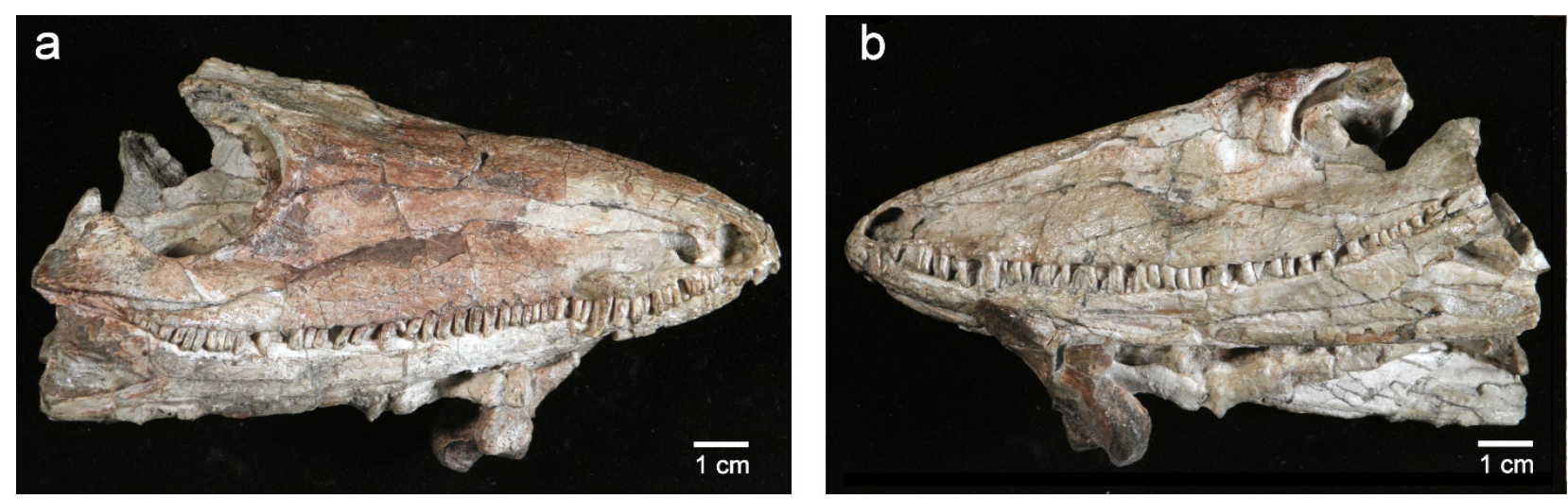

Fig. 1. Varanosaurus acutirostris (coll. number BSPHM 1901 XV 20) (a) right lateral view; (b) left lateral view.

Neutron tomography and three-dimensional reconstruction of the tomographic volume. This work is based upon experiments performed at the ANTARES instrument operated by FRM II at the Heinz Maier-Leibnitz Zentrum (MLZ), Garching, Germany. A description of the beamline is provided by M. Schulz et al. [10]. The radiographic images of the specimen were produced by using cold neutron radiation in the range between $5 \AA$ and $1 \AA$. The field of view was $150 \times 150$ $\mathrm{mm}$. The resolution of the camera was 2048 x 2048 pixels. The effective (projected) pixel size on the scintillation screen was $75 \mu \mathrm{m} \times 75 \mu \mathrm{m}$. The tomographic volume was reconstructed by means of the software Octopus 8.5 (Inside Matters; http://www.octopusreconstruction.com/en/home) using the "filtered backprojection algorithm". Processing of the raw projection data acquired parallel beam geometry. As a result a stack of horizontal tomographic slices, which represents the whole tomographic volume, was generated.

3D modelling and visualisation of cranial structures. The tomographic volume produced by the software Octopus was visualized in Fig. 2 by means of the software VGStudioMaxx. VGStudioMaxx also provided the tools for preparation of the virtual sections through the skull as shown in Figs. 2 c, e-g.

The 3D models of the teeth shown in Fig. 3 were generated following the method of $\mathrm{M}$. Laaß [11] and M. Laaß et al. [12]. Structures of interest such as the teeth were vectorized slice by slice with the segmentation tool of the software AMIRA 5.4 (FEI Visualization Sciences Group; http://www.vsg3d.com/). After smoothening and polygon reduction to 10 percent the regions of interest were saved as Wavefront files (Object files, OBJ). After this the object files were imported into the software SimLab Composer 2014 SP1 (Simlab Soft; http://www.simlabsoft.com/). Then the teeth objects were colored and exported as 3D-PDF.

Results

The tomographic investigation of the specimen of Varanosaurus acutirostris revealed the presence of plicidentine in the tooth roots for the first time in a varanopseid pelycosaur (Figs. 2, 
3). The infolded dentine was invisible from outside, because the tooth roots are almost completely covered by the jaw bones. Plicidentine is present both in the caniniform and postcaniniform teeth. The infolding is relatively simple, i.e. at the base of the tooth roots 4 to 5 folds can be observed, which become weaker towards the tooth crown (Fig 3).

a
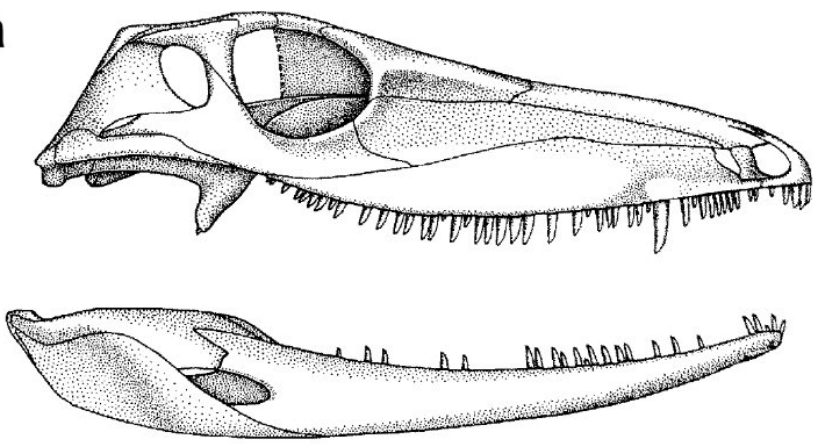

b

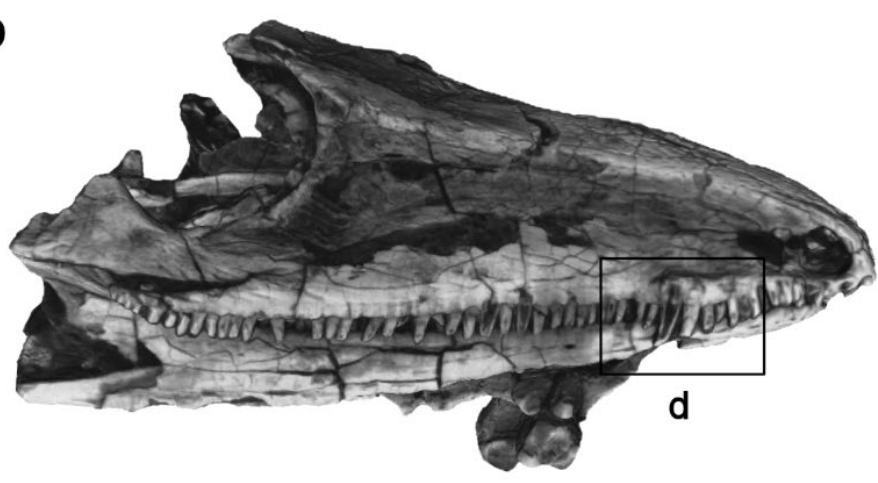

C

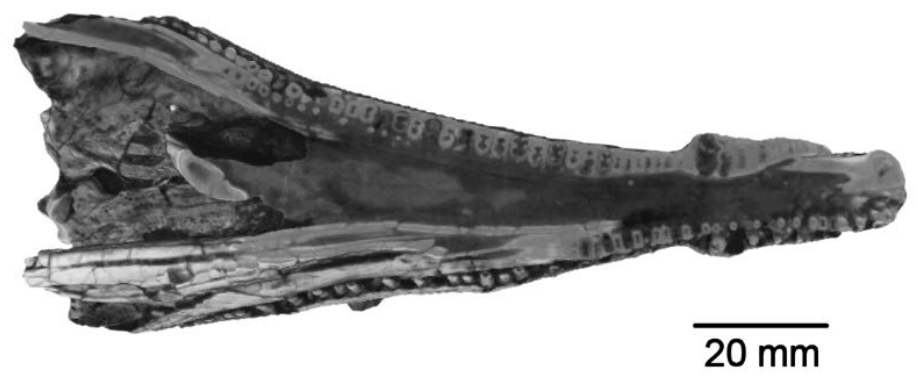

d

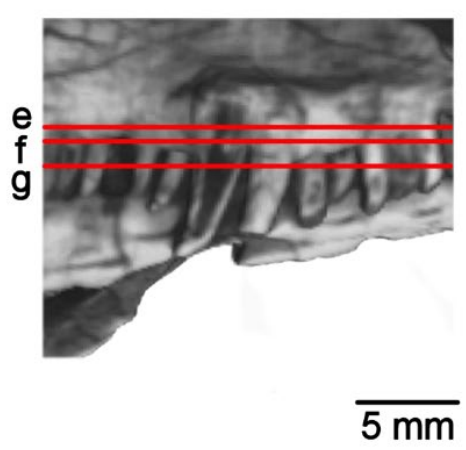

$\mathbf{e}$

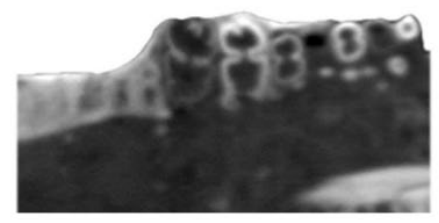

f

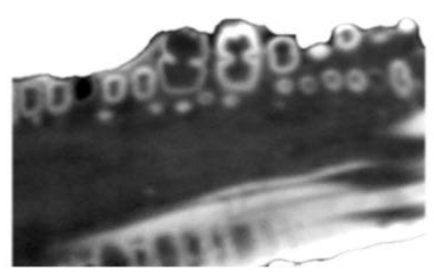

g

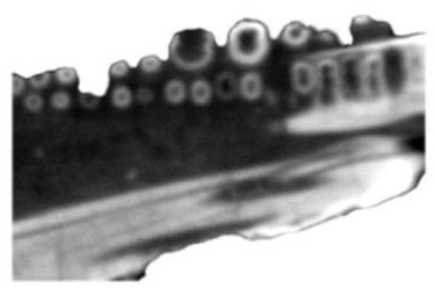

Fig. 2. Varanosaurus acutirostris (inventory number BSPHM 1901 XV 20) (a) reconstruction of the skull of Varanosaurus acutirostris from Berman et al. (1995); (b) Virtual 3D model of the skull in right lateral view; Note that the box marks the position of the image detail shown in (d);

(c) coronal section through the skull at the level of the teeth; (d) lateral detailed view on the jaws. Note that the red lines mark the positions of the coronal sections shown in (e), $(f)$, and (g); $(e),(f),(g)$ coronal sections through the teeth at different levels of the roots. 
If plicidentine indeed played a functional role to increase the area of attachment of tooth roots in the jaws to withstand the forces from feeding as proposed by H. Preuschoft et al. [13], J.D. Scanlon and M.S.Y. Lee [14] and M.J. MacDougall et al. [15], it can be expected that plicidentine is predominantly present in taxa with relatively shallow tooth roots in comparison to the crowns.

Therefore, the ratios of tooth root lengths vs. total tooth lengths are of special interest and were determined (see table 1) following the method of K.S. Brink et al. [2]. All measurements were taken from virtual sections through the 3D model of the skull.

Table 1. Measurements of the teeth of Varanosaurus acutirostris (BSPHM 1901 XV 20).

\begin{tabular}{ccccc}
\hline Teeth & $\begin{array}{c}\text { Total tooth } \\
\text { length [mm] }\end{array}$ & $\begin{array}{c}\text { Average crown } \\
\text { length [mm] }\end{array}$ & $\begin{array}{c}\text { Average root } \\
\text { length [mm] }\end{array}$ & $\begin{array}{c}\text { Root/total tooth } \\
\text { length [\%] }\end{array}$ \\
\hline $\begin{array}{c}\text { Postcaniniform } \\
\text { teeth }\end{array}$ & 5.7 & 3.9 & 1.8 & 30.1 \\
Caniniform teeth & 7.7 & 5.5 & 2.3 & 31.3 \\
\hline
\end{tabular}

As a first result it can be stated that there are no significant differences between the ratios of tooth root length vs. total tooth length of caniniform and postcaniniform teeth. Second, the average ratio of tooth root length vs. total tooth length is ca. $30 \%$ in Varanosaurus acutirostris, which shows that $V$. acutirostris possessed relatively shallow tooth roots.

\section{Discussion and conclusions}

Our measurements of the root vs. total tooth lengths in Varanosaurus acutirostris support the hypothesis that plicidentine seems to be restricted to taxa with relatively shallow tooth roots and probably played a functional role to strengthen tooth attachment. For comparison, K.S. Brink et al. [2] observed plicidentine in four sphenacodontid pelycosaurs (Ianthodon schultzei, Sphenacodon sp., Dimetrodon limbatus and Secodontosaurus obtusidens) with ratios of root vs. total tooth length smaller than 41\%. Interestingly, plicidentine was absent in the spenacodontid pelycosaur Dimetrodon grandis, which possesses relatively long tooth roots (50-57\%) in relation to the total tooth length [2]. The ratio of tooth root length vs. total tooth length of ca. $30 \%$ in Varanosaurus acutirostris fits well to the range of pelycosaur taxa with shallow tooth roots.

The first record of plicidentine in varanopseid pelycosaurs also shows that plicidentine was more widespread among basal synapsids that previously thought, which might be an indication that plicidentine was an ancient feature in early synapsids inherited from basal tetrapods. However, further investigations of other pelycosaur groups are necessary to clarify whether plicidentine evolved several times independently in early synapsid evolution or not.

Finally, the results show that non-destructive technologies such as neutron imaging are a very useful tool for investigation of non-mammalian synapsids. 
a

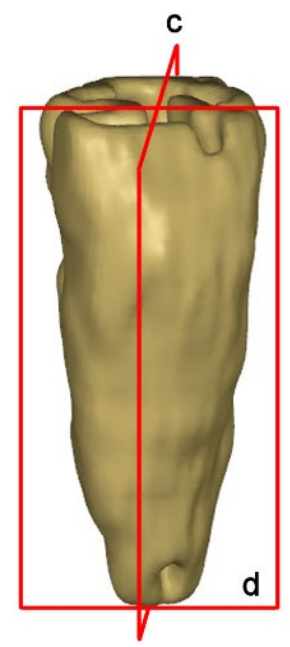

lingual

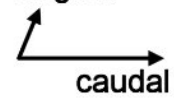

C

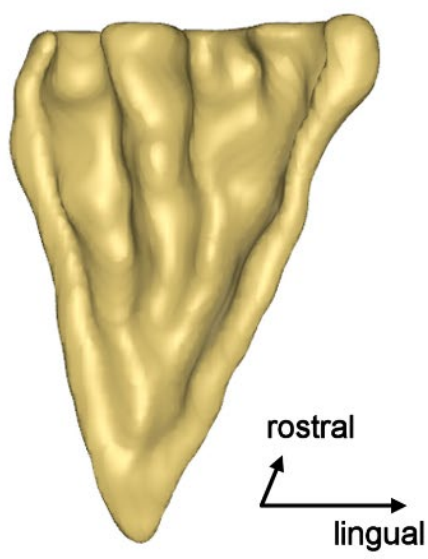

b
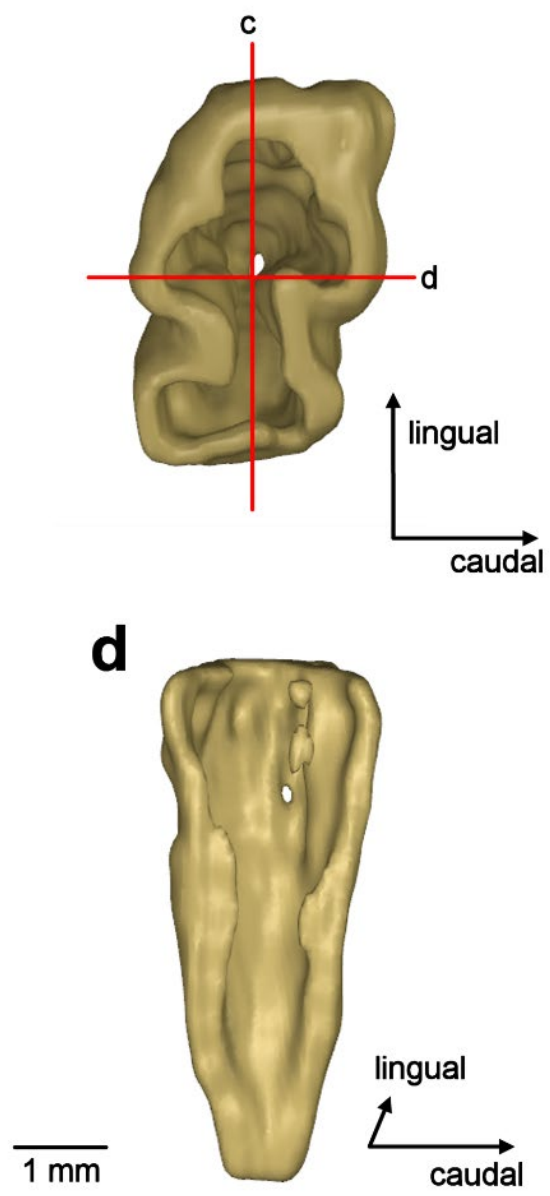

Fig. 3. Virtual 3D model of the left canine of Varanosaurus acutirostris (coll. number BSPHM 1901 XV 20) (a) lateral view; (b) view into the pulp cavity; Note the infolded dentine at the level of the tooth root; (c) and (d) sections through the tooth; Note that the red lines mark the positions of the sections in (a) and (b).

\section{Acknowledgements}

The authors gratefully acknowledge FRM II for financial support and the possibility to perform the neutron scattering measurements at the Heinz Maier-Leibnitz Zentrum (MLZ), Garching, Germany. We are also thankful to Oliver Rauhut, Munich, for access to material. Thomas Kuner, Heidelberg, provided the hard- and software for 3D modelling. The anonymous referees are thanked for their valuable comments on an earlier version of this paper.

\section{References}

[1] E.E. Maxwell, M.W. Caldwell, D.O. Lamoureux, The structure and phylogenetic distribution of amniote plicidentine. J. Vert. Paleontol. 31 (2011a) 553-561.

https://doi.org/10.1080/02724634.2011.557117 
[2] K.S. Brink, A.R.H. LeBlanc, R.R. Reisz, First record of plicidentine in Synapsida and patterns of tooth root shape change in Early Permian sphenacodontians. Naturwissenschaften (2014). https://doi.org/10.1007/s00114-014-1228-5

[3] K.S. Brink, R.R. Reisz, Hidden dental diversity in the oldest terrestrial apex predator Dimetrodon. Nat. Commun. 5 (2014). https://doi.org/10.1038/ncomms4269

[4] T.S. Kemp, Interrelationships of the Synapsida, in: M. J. Benton (Ed.) The Phylogeny and Classification of the Tetrapods (2), Clarendon Press, Oxford, 1988, pp. 1-22

[5] T.S. Kemp, The origin and evolution of mammals, Oxford Univ. Press, New York, 2005.

[6] D.S. Berman, R.R. Reisz, J.R. Bolt, D. Scott, The cranial anatomy and relationships of the synapsid Varanosaurus (Eupelycosauria: Ophiacodontidae) from the Early Permian of Texas and Oklahoma. Ann. Carnegie Mus. 58(2) (1995) 99-138.

[7] F. Broili, Permische Stegocephalen und Reptilien aus Texas. Palaeontogr. 51 (1904) 1-120.

[8] F. Broili, Über den Schädelbau von Varanosaurus acutirostris. Centralblatt für Mineralogie, Geologie, Paläontologie, Jahrbuch 1 (1914) 26-29.

[9] D.M.S. Watson, Notes on Varanosaurus acutirostris Broili. Ann. Mag. Nat. Hist. 13 (1914) 297-310. https://doi.org/10.1080/00222931408693483

[10] M. Schulz, B. Schillinger, E. Calzada, D. Bausenwein, P. Schmakat, T. Reimann, P. Böni, The new neutron imaging beam line ANTARES at FRM II. Restaur. Archäol (2015) 8.

[11] M. Laaß, Bone conduction hearing and seismic sensitivity of the Late Permian anomodont Kawingasaurus fossilis. J. Morphol. 276(2) (2014) 121-143. https://doi.org/10.1002/jmor.20325

[12] M. Laaß, B. Schillinger, I. Werneburg, Neutron tomography and X-ray tomography as tools for the morphological investigation of non-mammalian synapsids. Phys. Procedia 88 (2017) 100108. https://doi.org/10.1016/j.phpro.2017.06.013

[13] H. Preuschoft, W.-E. Reif, C. Loitsch, E. Tepe, The function of labyrinthodont teeth: big teeth in small jaws, in: N. Schmidt-Kittler, K. Vogel (Eds.), Constructional Morphology and Evolution, Springer-Verlag, Berlin-Heidelberg, 1991, pp. 151-171. https://doi.org/10.1007/9783-642-76156-0_12

[14] J.D. Scanlon, M.S.Y. Lee, Varanoid-like dentition in primitive snakes (Madtsoiidae). J. Herpetol. 36 (2002) 100-106. https://doi.org/10.1670/00221511(2002)036[0100:VLDIPS]2.0.CO;2

[15] M.J. MacDougall, A.R.H. LeBlanc, R.R. Reisz, Plicidentine in the Early Permian Parareptile Colobomycter pholeter, and its phylogenetic and functional significance among coeval members of the clade. PLoS ONE 9(5) (2014) e96559.

doi:10.1371/journal.pone.0096559. https://doi.org/10.1371/journal.pone.0096559 